\title{
Scutellaria baicalensis Georgi extract protects against alcohol-induced acute liver injury in mice and affects the mechanism of ER stress
}

\author{
QINGQING DONG ${ }^{1,2}$, FEI CHU ${ }^{2}$, CHENGZHU WU ${ }^{2}$, QIANG HUO ${ }^{2}$, \\ HUAIYONG GAN ${ }^{2,3}$, XIAOMING $\mathrm{LI}^{2}$ and $\mathrm{HAO} \mathrm{LIU}^{2}$ \\ ${ }^{1}$ Department of Pharmaceutical Preparation, The Second Affiliated Hospital of Bengbu Medical College, \\ Bengbu, Anhui 233004; Departments of ${ }^{2}$ Pharmacy and ${ }^{3}$ Pathology, \\ Bengbu Medical College, Bengbu, Anhui 233030, P.R. China
}

Received March 1, 2015; Accepted January 4, 2016

DOI: $10.3892 / \mathrm{mmr} .2016 .4941$

\begin{abstract}
The aims of the present study were to examine the hepatoprotective effect of Scutellaria baicalensis Georgi extract (Scutellariae Radix extract; SRE) against acute alcohol-induced liver injury in mice, and investigate the mechanism of endoplasmic reticulum (ER) stress. High performance liquid chromatography was used for the phytochemical analysis of SRE. Animals were administered orally with $50 \%$ alcohol $(12 \mathrm{ml} / \mathrm{kg}) 4 \mathrm{~h}$ following administration of doses of SRE every day for 14 days, with the exception of normal control group. The protective effect was investigated by measuring the levels of aspartate transaminase (AST), alanine transferase (ALT) and triglyceride (TG) in the serum, and the levels of glutathione (GSH) and malondialdehyde (MDA) in liver tissues. The levels of glucose-related protein 78 (GRP78) were detected using immunohistochemical localization and an enzyme-linked immunosorbent assay. Hepatocyte apoptosis was assessed using terminal-deoxynucleoitidyl transferase mediated nick end labeling. The SRE contained $31.2 \%$ baicalin. Pretreatment with SRE had a marked protective effect by reversing the levels of biochemical markers and levels of GRP78 in a dose-dependent manner. The results of the present study demonstrated that pretreatment with SRE exerted a marked hepatoprotective effect by downregulating the expression of GRP78, which is a marker of ER stress.
\end{abstract}

Correspondence to: Professor Hao Liu, Department of Pharmacy, Bengbu Medical College, 2600 East Ocean Avenue, Bengbu, Anhui 233030, P.R. China

E-mail: liuhao6886@foxmail.com

Key words: Scutellaria baicalensis georgi extract, hepatoprotective effect, acute alcohol-induced liver injury, endoplasmic reticulum stress, tunicamycin

\section{Introduction}

Alcoholic liver disease (ALD), caused by long-term alcohol consumption, is the broad term used to identify a number of alcohol-associated health problems, including mild alcoholic liver injury, alcoholic fatty liver, alcoholic hepatitis, alcoholic hepatic fibrosis (fatty liver) and alcoholic cirrhosis (1). The pathogenesis of the disease is complex, multifactorial and remains to be fully elucidated. Previous studies have found that endoplasmic reticulum (ER) stress, (ERS) which mediates liver cell apoptosis, is important in several liver diseases, including those associated with alcohol consumption (2-4).

The ER is one of the important organelles in the eukaryotic cell, which is responsible for protein synthesis, folding, assembly, transportation, lipid synthesis and calcium storage (5). Furthermore, when any of these processes are disrupted, it causes an accumulation of unfolded or misfolded proteins in the ER, and the cells trigger a stress response in the ER, known as the unfolded protein response (UPR) (6). This type of ERS is a self-protective mechanism, and appropriate levels are necessary to maintain ER and cellular homeostasis (7). However, severe or prolonged ERS can lead to the activation of lipogenesis, inflammation and apoptosis (8). A variety of factors can cause ERS, including viruses, oxidative stress and high levels of homocysteine (9). Notably, the mechanism of ERS during acute liver injury remains to be fully elucidated, rendering the identification of novel pharmacological treatment options difficult. Therefore, further examination of the association between ERS and ALD is necessary in order to develop efficient clinical drugs to treat this disease.

As oxidative stress is one of the predominant causes of ERS, it is necessary to screen the antioxidants of plant extracts prior to clinical use. Several medicinal plants contain antioxidants, which can be used to remove free radicals and protect cells during oxidative stress. Therefore, these types of plants may be particularly useful to treat the cellular stress observed in patients with ALD (10). One traditional Chinese medicinal plant of interest is Scutellariae baicalensis Georgi, known as Huang qin in Chinese, which is a perennial herb belonging to the Lamiaceae family (11). The peeled and dried root of 
this plant, known as Scutellariae Radix (SR), has a variety of therapeutic uses, and 295 compounds have been isolated from this antioxidant-rich herb to date, including flavonoids, phenylethanoid glycosides, and diterpenes among others (12). Furthermore, baicalin, which has two adjacent phenolic hydroxyl structures, is one of the major flavonoid components found in SR (13). The structure of baicalin indicates a high level of antioxidant activity, therefore, it may be critical during free radical scavenging and other activities involved in protecting cells against oxidative damage (14). In addition, SR extract (SRE) has been used as a traditional medicine to protect the liver during acute and chronic liver injury, including that caused by carbon tetrachloride, iron overload, acetyl ammonia chemicals and sword bean element A (15-18). However, the biological effects of SRE during alcohol-associated liver injury remain to be elucidated. In the present study, the effects of SRE on acute alcohol-induced liver injury were investigated in mice, and the mechanism underlying the protective effects of this and similar medicinal plants during ALD-associated ERS were investigated, providing theoretical and practical support for the development of novel protective therapeutic agents for the liver.

\section{Materials and methods}

Chemicals. Ethanol, methanol and acetic acid, of high performance liquid chromatography (HPLC) grade, were purchased from Nanjing Chemical Reagent Co., Ltd. (Nanjing China). Water was prepared using redistilled water equipment (Milli-Q Advantage A10; EMD Millipore, Billerica, MA, USA). All other chemicals used in the present study were of analytical grade and from Nanjing Chemical Reagent Co., Ltd. Mouse glutathione (GSH) and malondialdehyde (MDA) kits were obtained from Nanjing Jiancheng Bioengineering Institute (Nanjing, China). The glucose regulated protein $78 \mathrm{kD}$ (Grp78) enzyme-linked immunosorbent assay (ELISA) kit was purchased from Suzhou Calvin Biotechnology Co., Ltd. (Suzhou, China), the Terminal-deoxynucleoitidyl Transferase Mediated Nick End Labeling (TUNEL) kit was purchased from Nanjing KeyGEN Biotech Co., Ltd. (Nanjing China). Tiopronin was provided by He'nan New Yi Pharmaceutical Co., Ltd. (Xinxiang, China). Tunicamycin (TM) was obtained from Sigma-Aldrich (St. Louis, MO, USA). Antibody against GRP78 was purchased from Santa Cruz Biotechnology, Inc. (Dallas, TX, USA; cat. no. sc-13968). Baicalin with a purity of $>98 \%$ was used for the quantitative analysis of SRE, which was purchased from Dalian Meilun Biotech Co., Ltd (Dalian China).

Plant materials. Scutellartiae Radix methanol extract was provided by the Department of Pharmacy of Bengbu Medical College (Bengbu, China).

Analysis of SRE. The standard, baicalin, was used for the quantitative analysis of SRE. Baicalin $(9.1 \mathrm{mg})$ and Scutellariae Radix extract (10.1 mg), were dissolved in grade methanol with a constant volume of $10 \mathrm{ml}$. The HPLC apparatus (Agilent 1200 Series; Agilent Technologies, Santa Clara, CA, USA) was used for analysis. The analytical column was a Kromasil C18 column (250x4.6 mm i.d; $5 \mu \mathrm{m}$ particle size; AkzoNobel, Brewster, NY, USA), and the column temperature was maintained at $22^{\circ} \mathrm{C}$. The column eluent was monitored at ultraviolet $278 \mathrm{~nm}$. The chromatography was performed at room temperature with a flow rate of $1.0 \mathrm{ml} / \mathrm{min}$, and a $20 \mu \mathrm{l}$ volume was analyzed. The mobile phase comprised methanol:water (containing 2\% acetic acid) at a ratio of 50:50.

Animals. Male Kunming mice ( $\mathrm{n}=60$; weight, $20 \pm 2 \mathrm{~g}$; age, 4-5 weeks) were obtained from the Experimental Animal Center of Anhui medical University (Hefei, China). The animals were acclimatized for 1 week in standard conditions, with a temperature of $22^{\circ} \mathrm{C}$ [standard deviation $(\mathrm{SD})=2$ ], relative humidity of $55 \%(\mathrm{SD}=5 \%)$ and a $12 / 12 \mathrm{~h}$ light/dark cycle, with access to food and water ad libitum, prior to the experiments. All procedures were performed in strict accordance with the Use and Care of Laboratory Animals (National Research Council of USA, 1996) (19,20), and the current study was approved by the associated ethical regulations of Bengbu Medical College.

Acute alcohol-induced liver injury. The male mice were divided into the following six groups, each containing 10 mice: Normal control group; model group, group treated with $30 \mathrm{mg} / \mathrm{kg}$ tiopronin as a positive control; group treated with $40 \mathrm{mg} / \mathrm{kg}$ SRE; group treated with $80 \mathrm{mg} / \mathrm{kg} \mathrm{SRE}$; and group treated with $160 \mathrm{mg} / \mathrm{kg}$ SRE. The SRE and tiopronin were prepared by dissolving the extracts in $0.5 \%$ sodium carboxymethyl cellulose (CMC-Na; Shanghai Shenguang Food Chemicals Co., Ltd., Shanghai, China). The mice in normal control group and the model group were provided with equal volumes of the $0.5 \%$ CMC-Na solution. According to previous associated literature with minor adjustments (21-23), the mice were treated with the tiopronin $(30 \mathrm{mg} / \mathrm{kg})$ or SRE $(40,80$ or $160 \mathrm{mg} / \mathrm{kg}$ ) for 14 consecutive days via intragastric administration. At $\sim 4 \mathrm{~h}$ following each treatment, $50 \%$ alcohol $(12 \mathrm{ml} / \mathrm{kg})$ was orally administered to induce acute alcohol liver injury, whereas the mice in the normal (non-alcohol treated) group were orally administered with equal volumes of redistilled water.

TM-induced liver injury. TM is a common drug used to induce ERS. In order to further examine the association between the protective function of SRE in ERS in the liver, the present study also induced TM-induced liver injury in mice. Male mice were again divided into six groups (10 mice in each) in the aforementioned treatment groups. However, rather than alcohol administration following SRE treatment, the mice were orally administered with $1 \mathrm{mg} / \mathrm{kg}$ TM on the 14 th day. Blood samples $(\sim 1 \mathrm{ml})$ were collected $16 \mathrm{~h}$ following the final treatment by eye removal under ether (Nanjing Chemical Reagent Co., Ltd.) anesthesia, and these samples were used to detect the following serum biomarkers: Aspartate transaminase (AST), alanine transferase (ALT) and triglyceride (TG). All animals were subsequently sacrificed by cervical dislocation, and liver tissue was isolated for GSH and MDA marker, and histological analysis.

Serum biochemical measurements. The aforementioned blood samples were centrifuged at $1,125 \mathrm{x} \mathrm{g}$ for $15 \mathrm{~min}$ at room temperature. The levels of AST, ALT and TG in the serum samples were detected using an automatic biochemical analyzer (Hitachi 7100; Hitachi, Tokyo, Japan). 
A

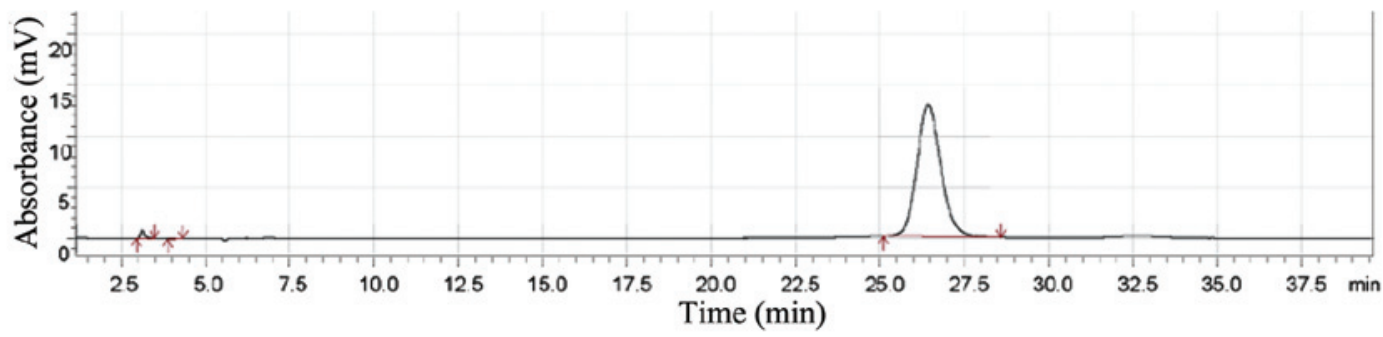

B

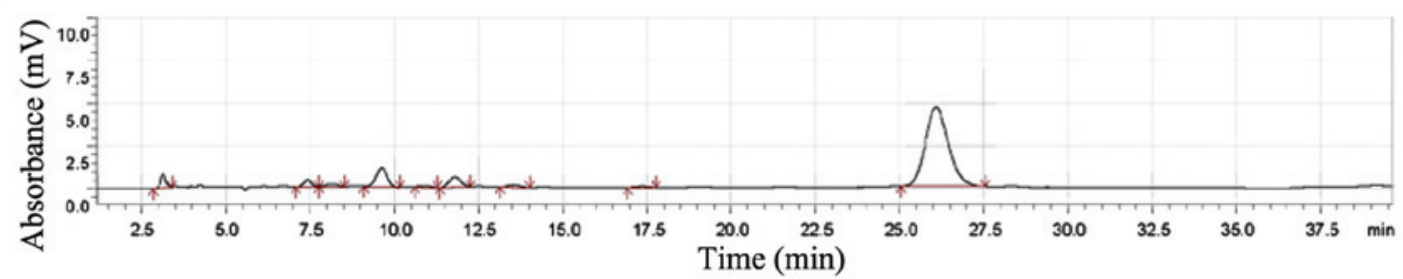

Figure 1. Chromatograms of (A) baicalin standard and (B) Scutellaria baicalensis extracts.

Evaluation of hepatic levels of MDA and GSH. In order to detect the hepatic lipid per oxidation and antioxidant capacity, accurately weighed liver tissue samples $(0.3 \mathrm{~g})$ were homogenized in nine volumes of physiological saline to obtain $10 \%(\mathrm{w} / \mathrm{v})$ homogenates. The homogenates were then centrifuged at 2,500 $\mathrm{x} \mathrm{g}$, for $15 \mathrm{~min}$ at $4^{\circ} \mathrm{C}$ and the supernatants were obtained, which were used for the assessment of MDA and GSH. Corresponding kits (Nanjing Jiancheng Bioengineering Institute) were used, according to the manufacturer's protocols.

Histopathological observation. Small sections of liver tissues were removed from the edges of the left liver lobe $(0.5 \mathrm{~cm})$ and fixed with $10 \%$ formaldehyde (BioSharp, Hefei, China). Following routine dehydration, transparency and paraffin embedding (Shanghai Yuanye Bio-Technology Co., Ltd., Shanghai, China), the sections (5 $\mu \mathrm{m}$ thick) were stained with hematoxylin and eosin (H\&E; Nanjing Jiancheng Bioengineering Institute), and the histomorphology was observed under a light microscope (Olympus CX21; Olympus Corporation, Tokyo, Japan).

ELISA. The reagents were provided in the Grp78 ELISA kit, and standard wells and testing sample wells were used. The kits were used according to the manufacturer's protocols. The standard (50 $\mu \mathrm{l})$ was added to the standard well. The mouse serum testing sample $(10 \mu \mathrm{l})$ and sample diluent $(40 \mu \mathrm{l})$ were added to the testing sample well. A blank well, with no additions, was included. HRP-conjugate reagent $(100 \mu \mathrm{l})$ was then added to each well, covered with an adhesive strip and incubated for $60 \mathrm{~min}$ at $37^{\circ} \mathrm{C}$. Each well was aspirated and washed, which was repeated four times for a total of five washes. Washing was performed by filling each well with wash solution $(400 \mu \mathrm{l})$ using a squirt bottle, manifold dispenser or auto-washer. The complete removal of liquid at each step is essential for optimal performance. Following the final wash, any remaining wash solution was removed by aspirating or decanting. The plate was inverted and blotted against clean paper towels. Chromogen solution A (50 $\mu \mathrm{l})$ and chromogen solution B (50 $\mu \mathrm{l})$ were added to each well, gently mixed and incubated for $15 \mathrm{~min}$ at $37^{\circ} \mathrm{C}$ in the dark. Stop solution $(50 \mu \mathrm{l})$ was then added to each well. The color in the wells are expected to change from blue to yellow. If the color in the wells is green or the color change does not appear uniform, the plate is tapped gently to ensure thorough mixing. The optical density (OD) at $450 \mathrm{~nm}$ was measured using a microplate reader (Synergy HT; Bio-Tek Instruments, Inc. Winooski, VT, USA) within 15 min.

Immunohistochemical assessment. In order to observe the dynamic changes in GRP78 distribution mice with acute liver injury, liver samples were paraffin-embedded and slices (5 $\mu \mathrm{m}$ thick) were prepared using a microtome (CM1950; Leica Microsystems GmbH, Wetzlar, Germany). Following dewaxing and hydration, antigen retrieval was conducted. The sections were immersed in $0.01 \mathrm{~mol} / \mathrm{l}$ citrate salt buffer $(\mathrm{pH}$ 7.0; Beijing Zhongshan Golden Bridge Biotechnology Co., Ltd., Beijing, China). The sections were then heated four times in a microwave oven for 6 min each time and then soaked in a 3\% (v/v) hydrogen peroxide solution (Nanjing Jiancheng Bioengineering Institute) for $30 \mathrm{~min}$ to block endogenous peroxidase activity. Following washing of the sections with phosphate-buffered saline (PBS) three times for $5 \mathrm{~min}$, rabbit serum was added to block any nonspecific binding sites. Subsequently, the slices were incubated with monoclonal rabbit anti-mouse GRP78 antibody (1:100) at room temperature overnight. Following washing with PBS, the slices were incubated with monoclonal biotinylated goat anti-rabbit IgG (1:50; BioSharp) for $30 \mathrm{~min} 37^{\circ} \mathrm{C}$, and were visualized using diaminobenzidine (DAB; Nanjing Jiancheng Bioengineering Institute). The cell nuclei were then stained using hematoxylin, and the sections underwent gradient alcohol dehydration and xylene (BioSharp) transparency prior to mounting. The liver sections were then observed under a light microscope (Olympus Corporation).

Terminal-deoxynucleotidyl transferase mediated nick end labeling (TUNEL). In order to identify apoptotic cells, TUNEL was performed on the dewaxed, hydrated, transparent liver sections ( $5 \mu \mathrm{m}$ thick) using TUNEL reaction mixture (Shanghai Beyotime Institute of Biotechnology, Shanghai, China) at $37^{\circ} \mathrm{C}$ for $1 \mathrm{~h}$. The slices were then immersed in $2 \mathrm{X}$ saline sodium 
citrate (Nanjing KeyGEN Biotech Co., Ltd.) for 15 min to terminate the reaction. Endogenous peroxidase activity was also blocked in the slices, and they were then stained with DAB and hematoxylin. The sections were then washed with $\mathrm{ddH}_{2} \mathrm{O}$ for $6 \mathrm{~min}$, rehydrated with a gradient of ethanol and soaked in xylene. Following mounting, the sections were observed under a light microscope (Olympus Corporation).

Statistical analysis. All experiments were repeated at least three times. Data are expressed as the mean \pm SD. The difference of data between groups was analyzed by the two-tailed Student's t-test and one-way analysis of variance using SPSS 17.0 software (SPSS, Inc., Chicago, IL, USA). $\mathrm{P}<0.05$ was considered to indicate a statistically significant difference.

\section{Results}

HPLC profiles of SRE. Baicalin is one of the primary active ingredients of Scutellaria baicalensis Georgi. Baicalin is a quality control indicator in several traditional Chinese medicine preparations that contain Scutellaria baicalensis Georgi. The present study analyzed the primary ingredient of SRE by HPLC, and the peak area in the chromatogram (Fig. 1) indicated that $100 \mathrm{mg}$ SRE contained $\sim 31.2 \mathrm{mg}$ baicalin.

ERS and the effects of acute alcohol-induced liver injury in mice. The serum levels of ALT and AST are important indicators of liver cell damage (24). The accumulation of fat is also a major pathological change observed in ALD, therefore, TG was used as a significant liver damage marker in the present study (25). As shown in Fig. 2A and B, compared with the normal group, the levels of serum ALT, AST and TG were increased following the administration of alcohol for the 14 days (all $\mathrm{P}<0.01$ ). MDA is an end product of lipid peroxidation, which has potent biological toxicity and can seriously damage the structure of the cell membrane, leading to cell swelling and necrosis (26). The level of MDA directly reflects the degree of organ oxidative damage. As shown in Fig. 2C, compared with the normal group, the levels of hepatic MDA were significantly increased in the alcohol-induced injury group $(\mathrm{P}<0.01)$. Furthermore, the levels of GSH, an endogenous oxygen free radical scavenger (27) were examined. Compared with the normal group, the levels of GSH were decreased in the alcohol-induced injury group $(\mathrm{P}<0.01$; Fig. $2 \mathrm{C})$. On observation with the naked eye, the livers isolated from mice in the control group were bright red with sharp edges and a glossy surface (Fig. 2D). However, the livers isolated from the mice in the alcohol-injured group had reduced luster and elasticity. The liver volume and capsular tension increased gradually, which were in accordance with the results of the biochemical analysis described above. Observed under a light microscope, the liver lobular structures were clear, and hepatocytes were arranged regularly in the control mice. Apparent damage was inspected in the alcohol-injured group, which had large areas of cell necrosis, mass inflammatory cell infiltration and fat vacuolization in the liver cells (Fig. 2E).

Effects of acute alcohol-induced ERS in mice. GRP78 is a well-known marker of ERS. To investigate the effects of acute alcohol-induced ERS in the mice, ELISA and
A
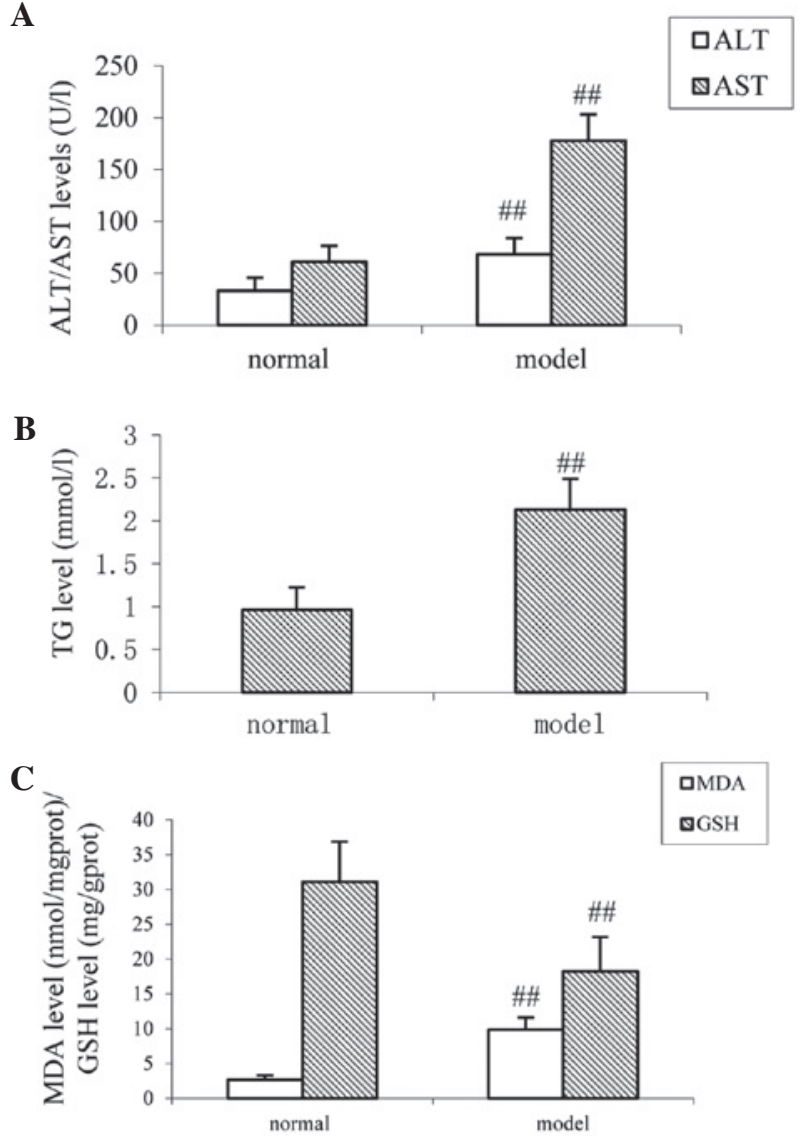

D

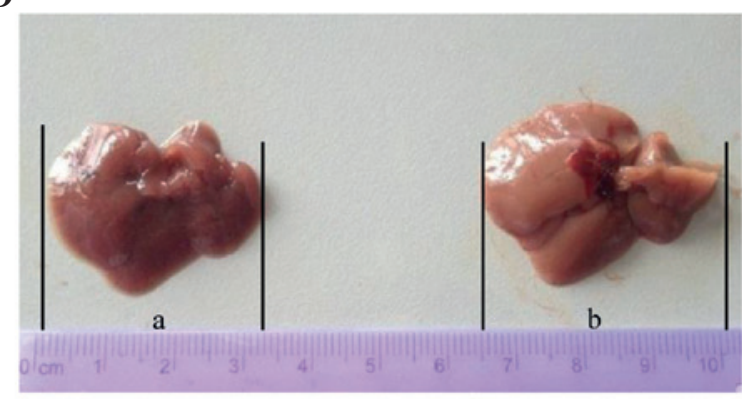

$\mathbf{E}$

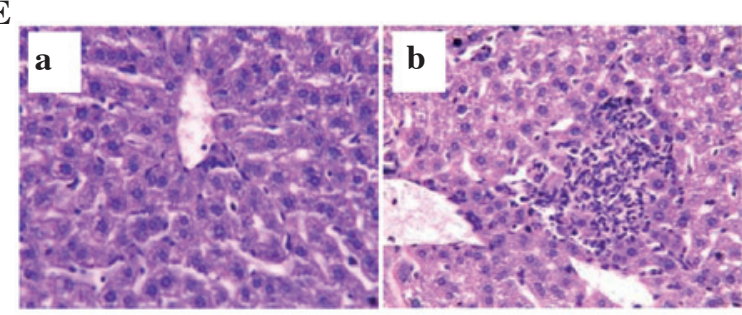

Figure 2. Effects of alcohol-induced liver injury. Serum levels of (A) ALT and AST, and (B) TG in mice with acute alcohol-induced liver injury. (C) Levels of MDA and GSH in the livers of mice with acute alcohol-induced liver injury. Values are presented as the mean \pm standard deviation $(n=10)$. ${ }^{\# \#} \mathrm{P}<0.01$, compared with the control group. (D) Comparison of liver tissue appearance: (a) normal control; (b) acute alcohol-injury. (E) Histological examination of acute alcohol-induced liver injury in mice (hematoxylin and eosin staining; magnification, $\mathrm{x} 400$ ). (a) Normal control group; (b) acute alcohol-injured group. AST, aspartate transaminase ALT, alanine transferase; TG, triglyceride; GSH, glutathione; MDA, malondialdehyde.

immunohistochemistry were used for the determination of ERS. A single dose of alcohol administration significantly increased the level of serum GRP78 in the ELISA $(\mathrm{P}<0.01)$ 
A

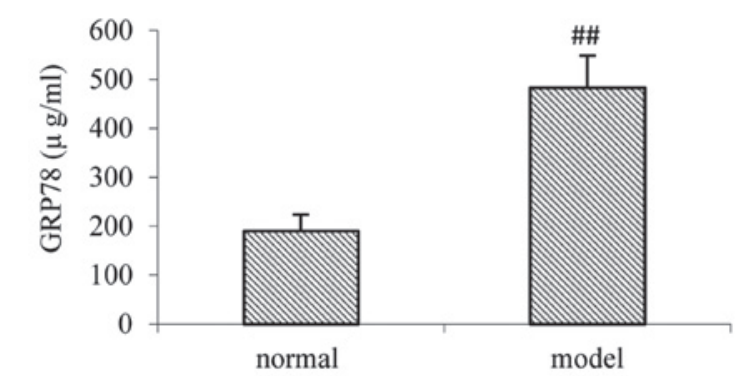

B

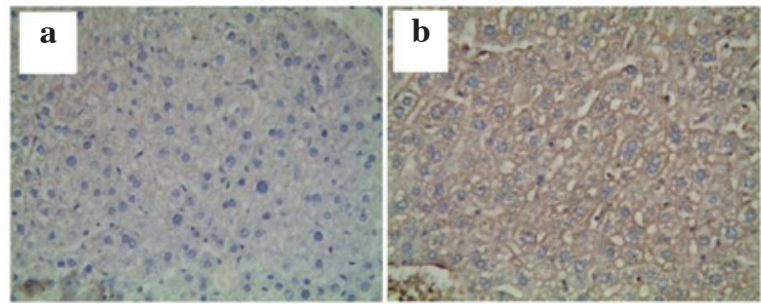

C

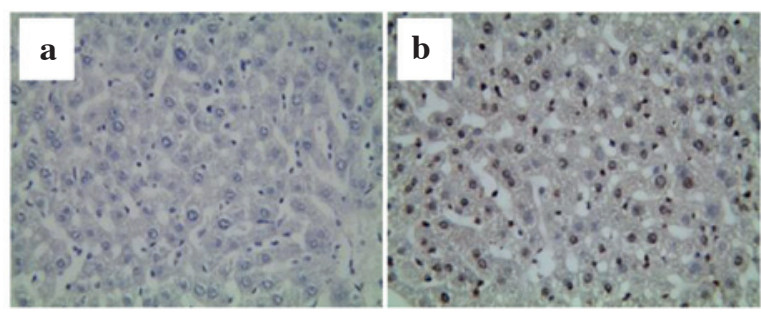

Figure 3. (A) Enzyme-linked immunosorbent assay for the protein level of GRP78 in acute alcohol-induced liver injury in mice. Values are presented as the mean \pm standard deviation $(n=10)$. ${ }^{\#} \mathrm{P}<0.01$, compared with the control group. (B) Distribution of hepatic GRP78 in acute alcohol-induced live injury in mice (magnification, $x 400$ ). (a) normal control group; (b) acute alcohol-injured group. (C) Hepatic apoptosis in alcohol-induced acute liver injury in mice using terminal-deoxynucleoitidyl transferase mediated nick end labeling (magnification, x400). (a) normal control group; (b) acute alcohol-injured group. GRP78, glucose-related protein 78 .

and in the hepatocytes, determined by immunohistochemistry (Fig. 3A and B). As shown in Fig. 3C, compared with the normal control group, the number of TUNEL-positive cells were elevated in the mice following the administration of alcohol. The above results suggested that ERS is important in alcohol-induced liver injury in mice, which mediated liver cell apoptosis.

Effects of SRE pretreatment on acute alcohol-induced liver injury in mice. As shown in Fig. 4A and B, compared with the normal group, the levels of serum ALT, AST and TG were all increased following administration of alcohol, on the 14th day of treatment. Pretreatment with 80 and $160 \mathrm{mg} / \mathrm{kg}$ SRE significantly inhibited the increases in ALT, AST and TG $(\mathrm{P}<0.05$ and $\mathrm{P}<0.01$, respectively) in a dose-dependent manner. Tiopronin pretreatment also exerted an analogous effect against acute alcohol liver injury mice by reducing the elevations of ALT, AST and TG ( $\mathrm{P}<0.01$; Fig. 4A). As shown in Fig. 4C, compared with the normal group, the levels of hepatic MDA significantly increased in the alcohol-injured group $(\mathrm{P}<0.01)$. However, the tissue concentrations of MDA were decreased significantly, in a dose-dependent manner, following pretreating with 40,80 or $160 \mathrm{mg} / \mathrm{kg}$ SRE (all $\mathrm{P}<0.01$ ).
Furthermore, the levels of GSH, an endogenous oxygen free radical scavenger were examined. Compared with the normal group, the levels of GSH were decreased in the alcohol-injured group $(\mathrm{P}<0.01)$. The concentrations of GSH in the liver were increased following treatment with $80(\mathrm{P}<0.05)$ and $160 \mathrm{mg} / \mathrm{kg}$ SRE $(\mathrm{P}<0.01)$ and $30 \mathrm{mg} / \mathrm{kg}$ tiopronin $(\mathrm{P}<0.01)$. On observation under a light microscope, the liver lobular structures were clear and hepatocytes were arranged regularly in the control mice. Apparent damage was observed in the alcohol-injured group, which had large areas of cell necrosis, mass inflammatory cell infiltration and fat vacuolization in the liver cells (Fig. 5A). These histopathological changes were reduced in the SRE-treated mice, in a dose-dependent manner. Furthermore, the highest dose of SRE improved the hepatic injury to a level similar to the effect observed in the tiopronin group.

SRE has a protective effect on acute alcohol-induced liver injury in mice by reducing ERS. The present study detected GRP78 in mice using ELISA and immunohistochemical examination. The serum levels of GRP78 were investigated using ELISA (Fig. 5B). Compared with the normal group, GRP78 was elevated significantly in the mice treated with alcohol alone $(\mathrm{P}<0.01)$, whereas pretreatment with SRE $(80$ or $160 \mathrm{mg} / \mathrm{kg}$ ) reduced this increase significantly $(\mathrm{P}<0.05$ and $\mathrm{P}<0.01$, respectively). For a comprehensive assessment of the effects of SRE against alcohol-induced acute liver injury, the present study also observed trace quantities of GRP78 in the normal control group (Fig. 5C), whereas this expression was enhanced in the alcohol group. Following pretreatment with SRE (40, 80 or $160 \mathrm{mg} / \mathrm{kg}$ ), the expression levels of GRP78 decreased in a dose-dependent manner. These results suggested that SRE protected against acute alcohol-induced liver injury by downregulating GRP78. The TUNEL technique was used to observe changes in liver cell apoptosis in acute alcohol-induced liver injury in mice following SRE pretreatment. As shown in Fig. 5D, the number of TUNEL-positive cells were elevated in the mice following the administration of alcohol, whereas SRE pretreatment markedly inhibited the alcohol-induced increase in apoptosis, in a dose-dependent manner.

Effects of SRE pretreatment on acute TM-induced liver injury in mice. To confirm the protective effects of SRE on acute alcohol-induced liver injury, and further examine the involved mechanism, the present study also examined the effects of this extract on acute TM-induced liver injury. The results revealed that SRE decreased the serum concentrations of ALT, AST and TG (Fig. 6A and B), as well as the tissue levels of MDA (Fig. 6C), compared with the untreated TM-induced model group. Histological examination revealed that pretreatment with SRE also alleviated the central vein necrosis, hepatocyte lesions and inflammatory infiltrates observed in the TM-induced mice (Fig. 7A). The protein concentrations of GRP78 (Fig. 7B and C) also increased in the TM-induced mice, which were notably decreased in the groups pretreated with SRE. Finally, similar to the alcohol-induced liver injury, TUNEL staining of the TM-induced samples indicated that the level of apoptosis was increased (Fig. 7D). However, pretreatment with SRE was again observed to limit these levels, suggesting that the effects of SRE on TM-induced ERS mimicked those observed during alcohol-induced liver injury. 
A

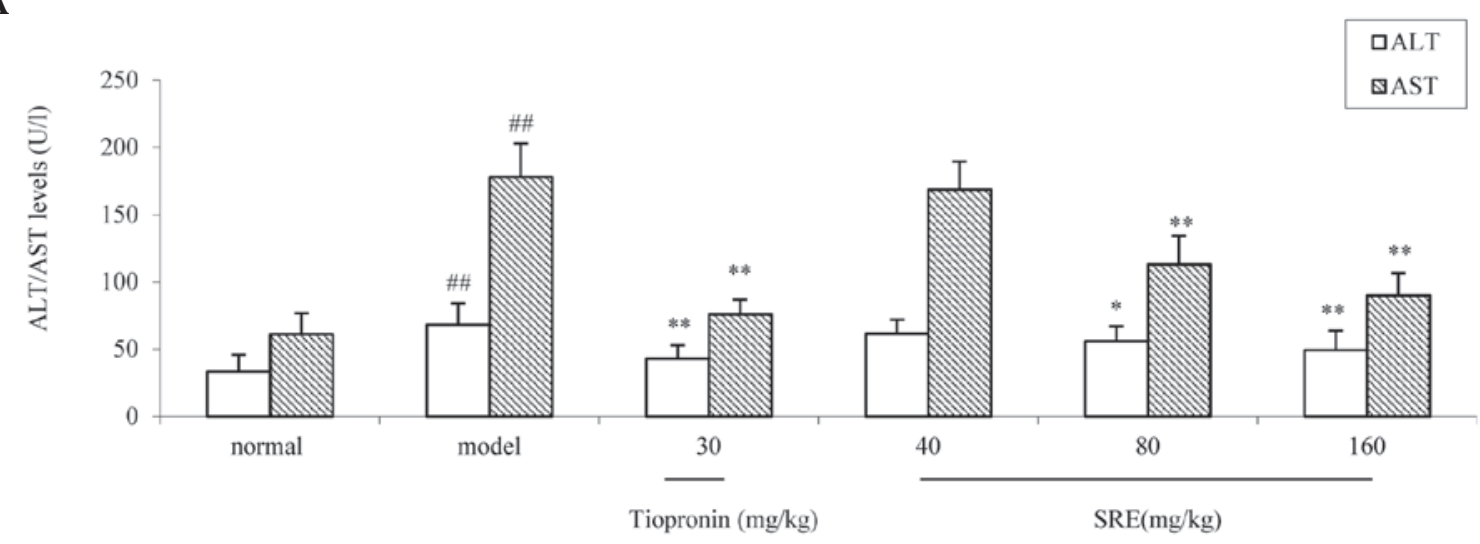

B
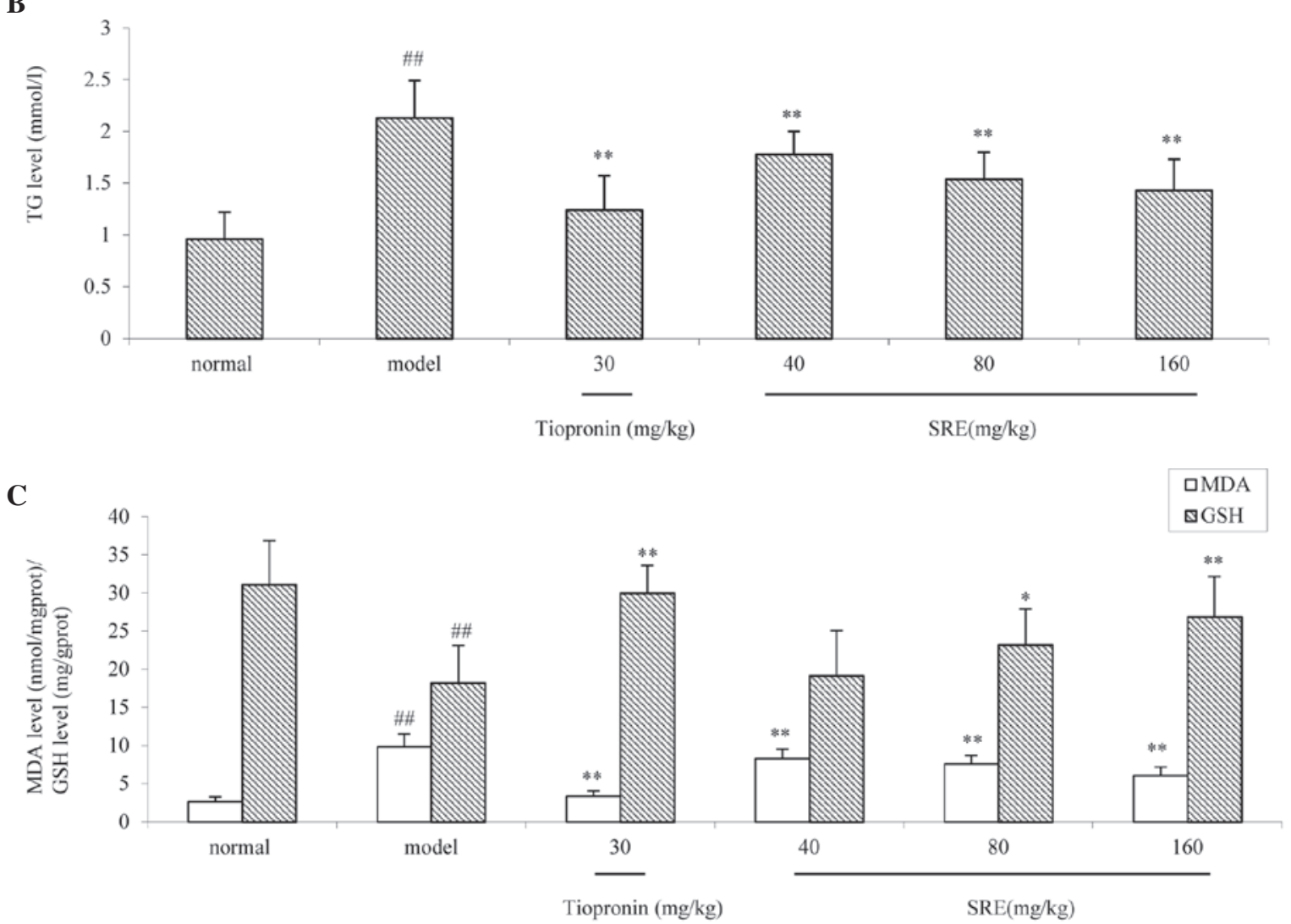

Figure 4. (A) Effect of SRE on serum levels of ALT and AST in mice with acute alcohol-induced liver injury. (B) Effect of SRE on serum levels of TG in mice with acute alcohol-induced liver injury. (C) Effect of SRE on levels of MDA and GSH in the livers of mice with acute alcohol-induced liver injury. All values are presented as the mean \pm standard deviation $(\mathrm{n}=10),{ }^{\# \#} \mathrm{P}<0.01$, compared with the control group; ${ }^{* *} \mathrm{P}<0.01$ and ${ }^{*} \mathrm{P}<0.05$, compared with the model group. SRE, Scutellaria baicalensis Georgi extract; AST, aspartate transaminase ALT, alanine transferase; TG, triglyceride; GSH, glutathione; MDA, malondialdehyde.

\section{Discussion}

The incidence of ALD is gradually increasing yearly, indicating how relatively small changes in lifestyle and diet can result in serious health and social development issues. However, the pathogenesis of ALD is complex and remains to be fully elucidated. The upregulation of ERS-associated signaling pathways likely indicates that apoptosis is also involved in alcohol-induced liver injury (28). The ER is an important net-like apparatus in cells, which functions to fold proteins, synthesize lipids and release calcium. The disruption of these physiological ER functions by oxidative stress, nutritional deficiency, viruses or free radicals, increases the number of unfolded proteins in the ER lumen, triggering the UPR (29). The UPR is a type of protective stress reaction of eukaryotic cells. When the number of unfolded proteins in the ER is too high, a series of pathological reactions, including fat formation, inflammation and apoptosis, are activated, which is often termed the ERS response (30). ERS can result in the expression and activation of sterol regulatory element binding protein and cause problems in lipid synthesis, leading to the increase of TG biosynthesis and excess fat deposit in the liver (31). It is currently hypothesized that, within mammalian cells, GRP78 functions to detect the accumulation of misfolded/unfolded proteins in the ER lumen, and when these levels exceed a certain threshold, GRP78 detaches from the chaperoned proteins and launches 
A

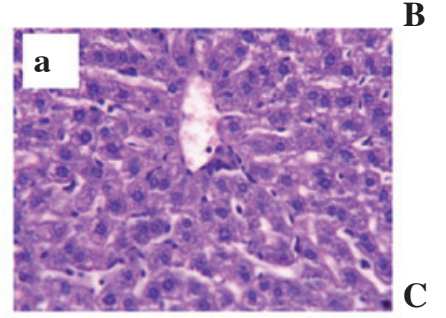

B
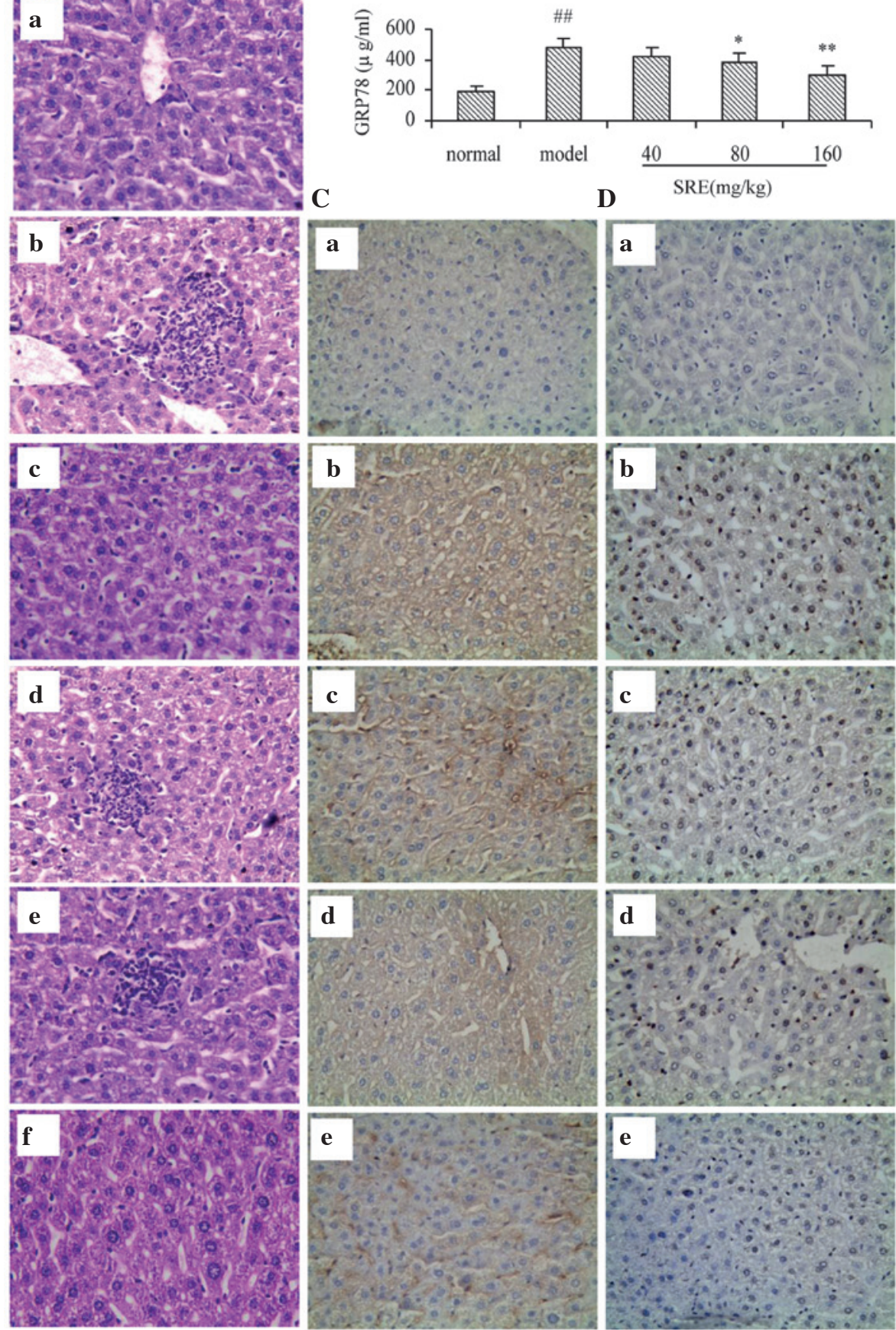

Figure 5. (A) Hepatoprotective effects of SRE on acute alcohol-induced hepatotoxicity in mice. Liver sections were stained with hematoxylin and eosin (magnification, x400). (a) Normal control group; (b) alcohol-induced group; (c) alcohol group treated with 30 mg/kg tiopronin; (d) alcohol group treated with $40 \mathrm{mg} / \mathrm{kg} \mathrm{SRE;} \mathrm{(e)} \mathrm{alcohol} \mathrm{group} \mathrm{treated} \mathrm{with} 80 \mathrm{mg} / \mathrm{kg}$ SRE; (f) alcohol group treated with $160 \mathrm{mg} / \mathrm{kg}$ SRE. (B) Effect of SRE on serum GRP78 in alcohol-injured mouse livers, determined using enzyme-linked immunosorbent assays. Values are presented as the mean \pm standard deviation $(\mathrm{n}=10)$. ${ }^{\# \#} \mathrm{P}<0.01$, compared with the control group; ${ }^{* *} \mathrm{P}<0.01$ and ${ }^{*} \mathrm{P}<0.05$, compared with the model group. (C) Effect of SRE on hepatic GRP78 in acute alcohol-injured mouse livers by immunohistochemical (magnification, x400). (D) Representative images of hepatic apoptosis in mice with alcohol-induced acute liver injury (terminal-deoxynucleoitidyl transferase mediated nick end labeling; magnification, x400). (C and D): (a) Normal control; (b) alcohol-induced; (c) alcohol group treated with $40 \mathrm{mg} / \mathrm{kg}$ SRE; (d) alcohol group treated with $80 \mathrm{mg} / \mathrm{kg}$ SRE; (e) alcohol group treated with $160 \mathrm{mg} / \mathrm{kg}$ SRE, Scutellaria baicalensis Georgi extract; GRP78, glucose-related protein 78.

a series of complex reactions. Therefore, GRP78 is a crucial marker of ERS (32). This mechanism allows the cells to survive and maintain homeostasis. However, when UPR cannot maintain cell survival, ERS can result in the upregulation of a series of detrimental signaling pathways, including apoptosis (33). Therefore, in the present study, GRP78 was selected as an index reflecting ERS. The results of the present study demonstrated that the levels of serum ALT, AST and TG were increased in alcohol-induced injury model group. On observation under a light microscope, there were large areas of cell necrosis, mass inflammatory cell infiltration and fat vacuolization in the liver cells of the model mice livers. The above results suggested 
A

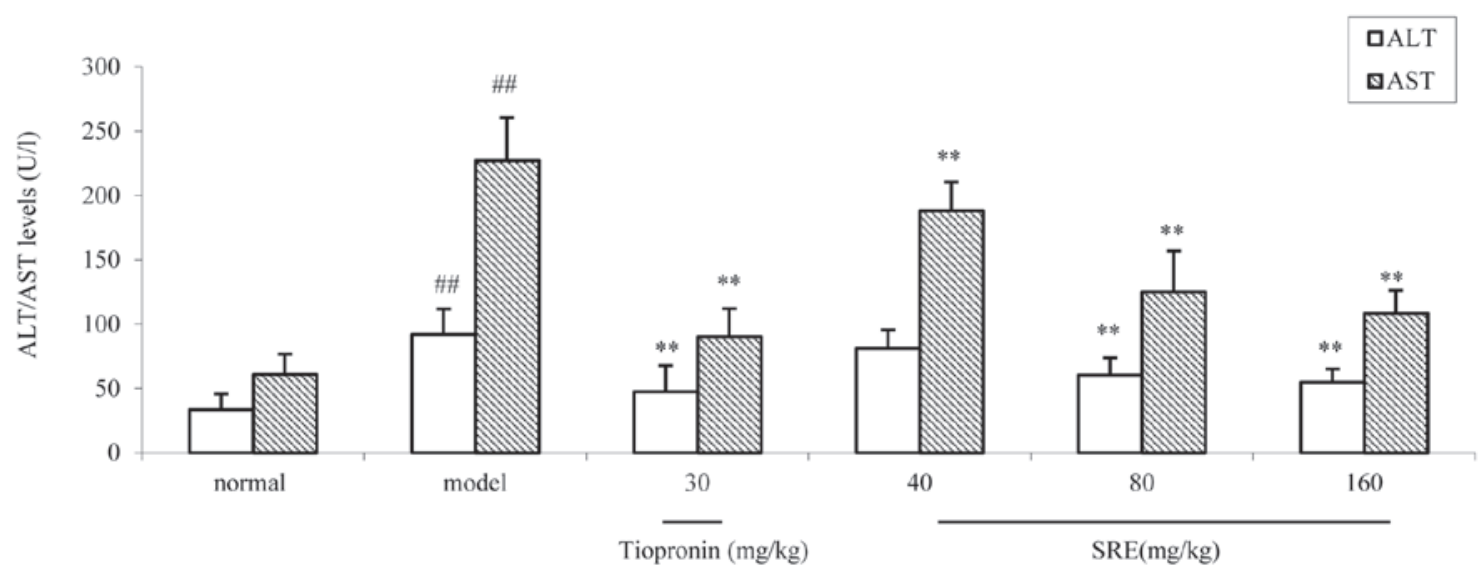

$\mathbf{B}$
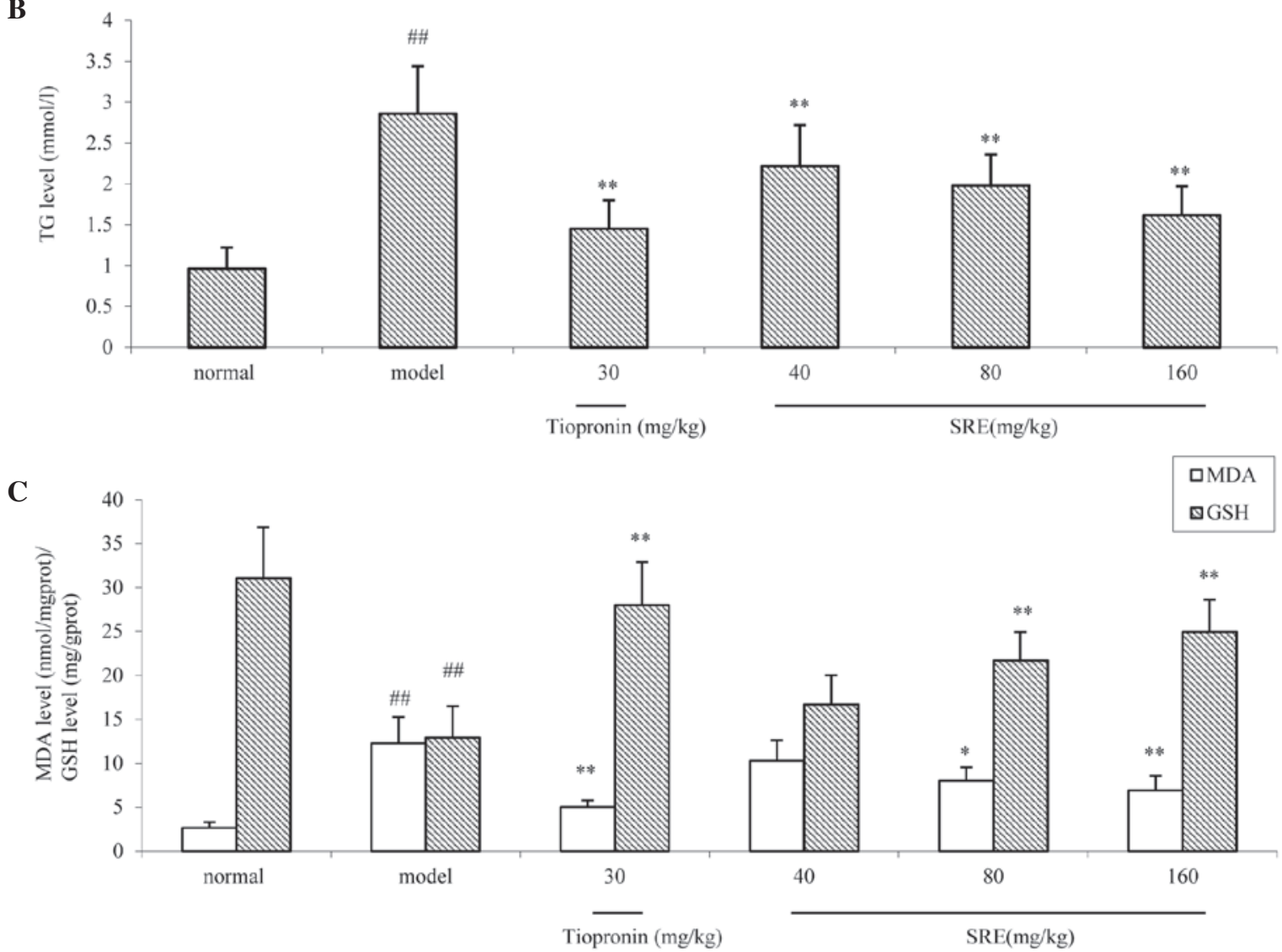

Figure 6. (A) Effect of SRE on serum levels of ALT and AST levels in acute TM-induced liver injury in mice. (B) Effect of SRE on serum levels of TG in TM-induced liver injury in mice. (C) Effect of SRE on levels of MDA and GSH in the livers of mice with TM-induced liver injury (n=10). All values are presented as the mean \pm standard deviation $(\mathrm{n}=10)$. ${ }^{\# \#} \mathrm{P}<0.01$, compared with the control group; ${ }^{* *} \mathrm{P}<0.01$ and ${ }^{*} \mathrm{P}<0.05$, compared with the model group. Scutellaria baicalensis Georgi extract; GRP78, glucose-related protein 78; AST, aspartate transaminase ALT, alanine transferase; TG, triglyceride; GSH, glutathione; MDA, malondialdehyde; TM, tunicamycin.

the successful construction of an alcohol-induced liver injury mouse model. Compared with the normal group, the protein expression levels of GRP78, determined by immunohistochemical examination and ELISA, were significantly enhanced in the alcohol-induced injury group. Compared with the normal control group, the number of TUNEL-positive cells was elevated in the mice following the administration of alcohol. In conclusion, ERS, which mediated liver cell apoptosis, was involved in the physiological and pathological processes of alcohol-induced liver injury, as one aspect of the pathogenesis.

There are currently a number of drugs available to treat ALD, each with its own distinct effects. However, to date, there is no single drug that can halt or reverse this process. Thus, more attention has been paid to the pathogenesis of ALD, and emphasis has been placed on screening for a reliable, curative drug to protect against alcohol-induced liver injury by reducing liver cell ERS. Evidence also indicates that ALD may cause liver cell apoptosis by inducing ERS with high levels of homocysteine and added oxidative stress (34). Therefore, it is necessary to screen antioxidants from plant extracts prior to clinical use. SR is a commonly used Chinese traditional medicine, and reports have also suggested that SR has antioxidant properties. However, whether SR can protect the liver from alcohol abuse-associated injury has not been 
A
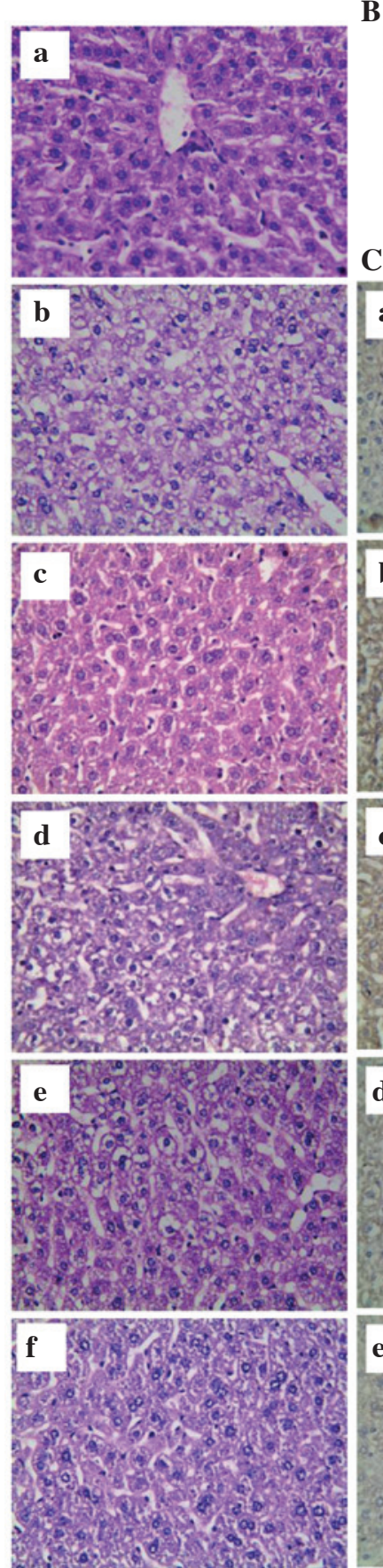

B

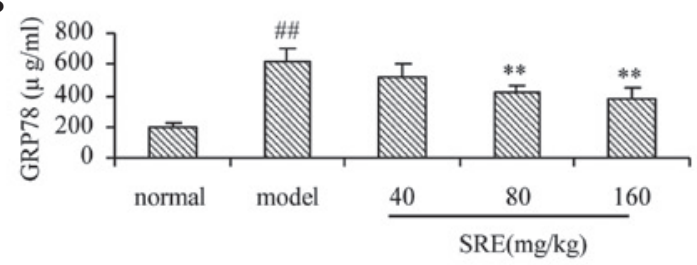

D
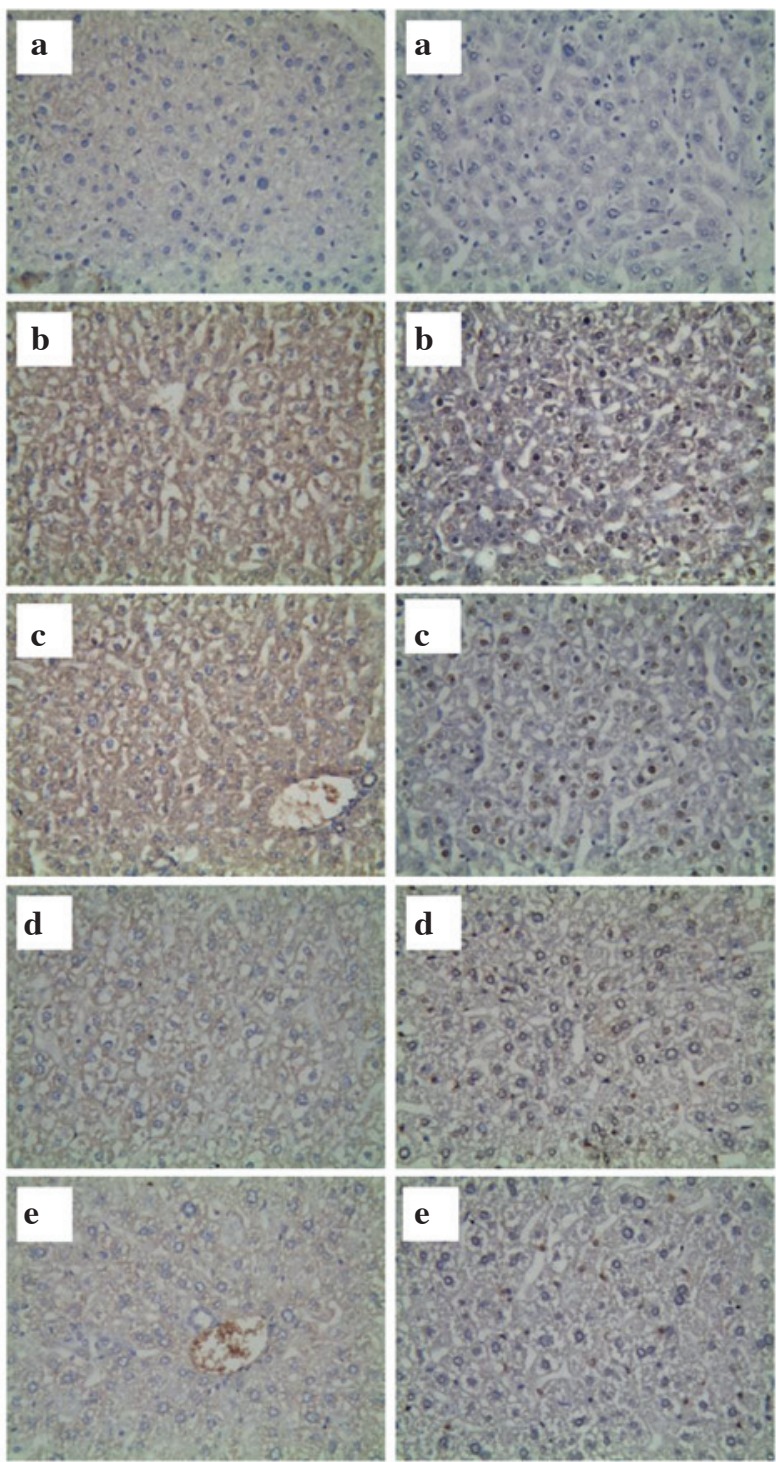

Figure 7. (A) Hepatoprotective effects of SRE on TM-induced hepatotoxicity in mice. Liver sections were stained with hematoxylin and eosin (magnification, x400). (a) Normal control group; (b) TM-induced group; (c) TM group treated with $30 \mathrm{mg} / \mathrm{kg}$ tiopronin; (d) TM group treated with $40 \mathrm{mg} / \mathrm{kg}$ SRE; (e) TM group treated with $80 \mathrm{mg} / \mathrm{kg} \mathrm{SRE}$; (f) TM group treated with $160 \mathrm{mg} / \mathrm{kg}$ SRE. (B) Effect of SRE on serum GRP78 in TM-injured mouse livers, determined using enzyme-linked immunosorbent assays. Values are presented as the mean \pm standard deviation $(\mathrm{n}=10) .{ }^{\#} \mathrm{P}<0.01$, compared with the control group; ${ }^{* *} \mathrm{P}<0.01$, compared with the model group. (C) Effect of SRE on hepatic GRP78 in TM-injured mouse livers by immunohistochemical analysis (magnification $\mathrm{x} 400$ ). (D) Representative images of hepatic apoptosis in TM-induced acute liver injury in mice using terminal-deoxynucleoitidyl transferase mediated nick end labeling (magnification, $x 400$ ): (C and D): (a) Normal control group; (b) TM-induced group; (c) TM group treated with $40 \mathrm{mg} / \mathrm{kg}$ SRE; (d) TM group treated with $80 \mathrm{mg} / \mathrm{kg}$ SRE; (e) TM group treated with $160 \mathrm{mg} / \mathrm{kg}$ SRE. SRE, Scutellaria baicalensis Georgi extract; GRP78, glucose-related protein 78; TM, tunicamycin.

established. Therefore, in the present study, the hepatoprotective effect and underlying molecular mechanism of SRE in acute alcohol-induced liver injury were investigated in a mouse model.

In the present study, a number of markers were used to measure liver function. ALT and AST are usually localized in the liver cells, however, during liver injury, these markers leak from the damaged cells into the blood (35). The decreases in AST and ALT in mice pretreated with SRE provide an indication of improved liver function, demonstrating that SRE likely stabilizes the cytomembrane and prevents the damage of hepatic tissue (36). MDA is the final product of lipid 
peroxidation, the levels of which indirectly reflect the degree of free radical damage. MDA is also an important index of liver cell recovery following treatment. By contrast, GSH is a scavenger of low molecular weight components, including free radicals and lipid peroxide radicals, and is the substrate of GSH peroxidase. Therefore, GSH is a direct measure of liver antioxidant capacity in the body (37).

Using these markers, the present study found that oxidative stress was a primary factor during acute alcohol-induced liver injury in mice. Furthermore, the protective abilities of SRE were demonstrated, as shown by the decreasing levels of each of the serum markers and MDA, and inhibiting the decrease of GSH activity. In addition, compared with the liver sections from the alcohol-induced injury group, the sections obtained from the mice treated with alcohol and SRE had lower levels of liver cell swelling, inflammation and fat vacuole formation.

In the present study, compared with the normal group, liver tissue isolated from the alcohol group showed pathological damage, and protein levels in the liver were elevated, confirming the involvement of ERS in acute alcohol-induced liver injury. These changes, and thus overall ERS, were also prevented following SRE treatment. Therefore the results of the present study confirmed that the protective effect of SRE against alcohol-induced liver injury may occur through the maintenance of ER homeostasis and the protection against ERS mediated hepatocyte apoptosis. In order to further evaluate the effect of SRE in acute alcohol-induced apoptosis, TUNEL assays were performed. These results indicated that treatment with SRE effectively prevented alcohol-induced DNA damage. In addition, a similar protective effect to that of SRE by inhibiting ERS was observed in mice with TM-induced injury.

In conclusion, the present study demonstrated that SRE exerted a hepatoprotective effect against acute alcohol-induced liver injury in mice through the downregulation of GRP78 and inhibition of ERS, resulting in regulated blood lipid levels and normal levels of apoptosis. However, the complete mechanism of SRE in the double-edged function of ERS in protecting liver cells requires additional investigation. The results of the present study suggest that believe that SRE may be a suitable candidate for the pharmacological treatment of ALD and warrants further investigation.

\section{Acknowledgements}

This study was supported by the National Natural Science Foundation of China (grant no. 81372899), the Natural Science Foundation of Anhui Province (grant no. 090413135) and the Key Project of Natural Science Research of the Education Department of Anhui Province, China (grant no. KJ2012A202).

\section{References}

1. Chen P, Stärkel P, Turner JR, Ho SB and Schnabl B Dysbiosis-induced intestinal inflammation activates tumor necrosis factor receptor I and mediates alcoholic liver disease in mice. Hepatology 61: 883-894, 2015.

2. Galligan JJ, Fritz KS, Backos DS, Shearn CT, Smathers RL, Jiang H, MacLean KN, Reigan PR and Petersen DR: Oxidative stress-mediated aldehyde adduction of GRP78 in a mouse model of alcoholic liver disease: Functional independence of ATPase activity and chaperone function. Free Radic Biol Med 73: 411-420, 2014.
3. Chen L, Ren F, Zhang H, et al: Inhibition of glycogen synthase kinase $3 \beta$ ameliorates D-GalN/LPS-induced liver injury by reducing endoplasmic reticulum stress-triggered apoptosis. PloS one 7: e45202, 2012

4. Fredriksson L, Wink S, Herpers B, Benedetti G, Hadi M, de Bont H, Groothius G, Luijten M, Danen E, de Graauw M, et al: Drug-induced endoplasmic reticulum and oxidative stress responses independently sensitize toward $\mathrm{TNF} \alpha$-mediated hepatotoxicity. Toxicol Sci 140: 144-159, 2014

5. Tanjore H, Cheng DS, Degryse AL, Zoz DF, Abdolrasulnia R, Lawson WE and Blackwell TS: Alveolar epithelial cells undergo epithelial-to-mesenchymal transition in response to endoplasmic reticulum stress. J Biol Chem 286: 30972-30980, 2011.

6. Cheng Q, Zhou Y, Liu Z, Zhang L, Song G, Guo Z, Wang W, Qu X, Zhu Y and Yang D: An alternatively spliced heat shock transcription factor, OsHSFA2dI, functions in the heat stress-induced unfolded protein response in rice. Plant Biol (Stuttg) 17: 419-429, 2015.

7. Baek HA, Kim do S, Park HS, Jang KY, Kang MJ, Lee DG, Moon WS, Chae HJ and Chung MJ: Involvement of endoplasmic reticulum stress in myofibroblastic differentiation of lung fibroblasts. Am J Respir Cell Mol Biol 46: 731-739, 2012.

8. Tan TC, Crawford DH, Jaskowski LA, Subramaniam VN, Clouston AD, Crane DI, Bridle KR, Anderson GJ and Fletcher LM: Excess iron modulates endoplasmic reticulum stress-associated pathways in a mouse model of alcohol and high-fat diet-induced liver injury. Lab Invest 93: 1295-1312, 2013.

9. Xiao B, Cui LM, Ma DJ, Liu SP and Zhang XW: Endoplasmic reticulum stress in diethylnitrosamine-induced rat liver cancer. Oncol Lett 7: 23-27, 2014.

10. Zhu XY, Zhang ZL, Li P, Liang WY, Feng XR and Liu ML: Shenyuan, an extract of American Ginseng and Corydalis Tuber formula, attenuates cardiomyocyte apoptosis via inhibition of endoplasmic reticulum stress and oxidative stress in a porcine model of acute myocardial infarction. J Ethnopharmacol 150: 672-681, 2013

11. Wang H, Cao J, Xu S, Gu D, Wang Y and Xiao S: Depletion of high-abundance flavonoids by metal complexation and identification of low-abundance flavonoids in Scutellaria baicalensis Georgi. J Chromatogr A 1315: 107-117, 2013.

12. Tsai CL, Lin YC, Wang HM and Chou TC: Baicalein, an active component of Scutellaria baicalensis, protects against lipopolysaccharide-induced acute lung injury in rats. J Ethnopharmacol 153: 197-206, 2014.

13. Orzechowska B, Chaber R, Wiśniewska A, Pajtasz-Piasecka E, Jatczak B, Siemieniec I, Gulanowski B, Chybicka A, Błach-Olszewska Z: Baicalin from the extract of Scutellaria baicalensis affects the innate immunity and apoptosis in leukocytes of children with acute lymphocytic leukemia. Int Immunopharmacol 23: 558-567, 2014.

14. Kim JK, Kim YS, Kim Y, Uddin MR, Kim YB, Kim HH, Park SY, Lee MY, Chung SO and Park SU: Comparative analysis of flavonoids and polar metabolites from hairy roots of Scutellaria baicalensis and Scutellaria lateriflora. World J Microbiol Biotechnol 30: 887-892, 2014.

15. Sun H, Che QM, Zhao X and Pu XP: Antifibrotic effects of chronic baicalein administration in a CCl4 liver fibrosis model in rats. Eur J Pharmacol 631: 53-60, 2010.

16. Zhao Y, Li H, Gao Z and Xu H: Effects of dietary baicalin supplementation on iron overload-induced mouse liver oxidative injury. Eur J Pharmacol 509: 195-200, 2005.

17. Jang SI, Kim HJ, Hwang KM, Jekal SJ, Pae HO, Choi BM, Yun YG, Kwon TO, Chung HT and Kim YC: Hepatoprotective effect of baicalin, a major flavone from Scutellaria radix, on acetaminophen-induced liver injury in mice. Immunopharmacol Immunotoxicol 25: 585-594, 2003.

18. Liu LL, Gong LK, Wang H, Xiao Y, Wu XF, Zhang YH, Xue X, Qi M and Ren J: Baicalin protects mouse from concanavalin A-induced liver injury through inhibition of cytokine production and hepatocyte apoptosis. Liver Int 27: 582-591, 2007.

19. Bayne K: Revised guide for the care and use of laboratory animals available. American Physiological Society. Physiologist 39: 119, 208-111, 1996.

20. Clark J, Gebhart GF, Gonder JC, Keeling ME and Kohn DF: The 1996 guide for the care and use of laboratory animals. ILAR J 38: 41-48, 1997.

21. Yi J, Xia W, Wu J, Yuan L, Wu J, Tu D, Fang J and Tan Z: Betulinic acid prevents alcohol-induced liver damage by improving antioxidant system in mice. J Vet Sci 15: 141-148, 2014. 
22. Tang CC, Huang HP, Lee YJ, Tang $\mathrm{YH}$ and Wang CJ: Hepatoprotective effect of mulberry water extracts on ethanol-induced liver injury via anti-inflammation and inhibition of lipogenesis in C57BL/6 J mice. Food Chem Toxicol 62: 786-796, 2013.

23. Gao HY, Huang J, Wang HY, Du XW, Cheng SM, Han Y, Wang LF, Li GY and Wang JH: Protective effect of Zhuyeqing liquor, a Chinese traditional health liquor, on acute alcohol-induced liver injury in mice. J Inflamm (Lond) 10: 30, 2013.

24. Al-Sayed E, El-Lakkany NM, Seif El-Din SH, Sabra AN and Hammam OA: Hepatoprotective and antioxidant activity of Melaleuca styphelioides on carbon tetrachloride-induced hepatotoxicity in mice. Pharm Biol 52: 1581-1590, 2014.

25. Lu KH, Tseng HC, Liu CT, Huang CJ, Chyuan JH and Sheen LY: Wild bitter gourd protects against alcoholic fatty liver in mice by attenuating oxidative stress and inflammatory responses. Food Funct 5: 1027-1037, 2014

26. Liu H, Qi X, Cao S and Li P: Protective effect of flavonoid extract from Chinese bayberry (Myrica rubra Sieb. et Zucc.) fruit on alcoholic liver oxidative injury in mice. J Nat Med 68: 521-529, 2014.

27. Cui Y, Ye Q, Wang H, Li Y, Yao W and Qian H: Hepatoprotective potential of Aloe vera polysaccharides against chronic alcohol-induced hepatotoxicity in mice. J Sci Food Agric 94 1764-1771, 2014

28. Wu D and Cederbaum AI: Inhibition of autophagy promotes CYP2E1-dependent toxicity in HepG2 cells via elevated oxidative stress, mitochondria dysfunction and activation of p38 and JNK MAPK. Redox Biol 1: 552-565, 2013.

29. Brandizzi F, Frigerio L, Howell SH and Schäfer P: Endoplasmic reticulum-shape and function in stress translation. Front Plant Sci 5: 425, 2014.
30. Yamada H, Nakajima T, Domon H, Honda T and Yamazaki K: Endoplasmic reticulum stress response and bone loss in experimental periodontitis in mice. J Periodontal Res 50: 500-508, 2015.

31. Sun LN, Zhou DF, Zhou JY, Zhao CY and Zhen Z: Role of endoplasmic reticulum stress in alcoholic liver disease-related hepatocyte apoptosis. Zhonghua Gan Zang Bing Za Zhi 20: 35-39, 2012 (In Chinese).

32. Kavitha CV, Jain AK, Agarwal C, Pierce A, Keating A, Huber KM, Serkova NJ, Wempe MF, Agarwal R and Deep G: Asiatic acid induces endoplasmic reticulum stress and apoptotic death in glioblastoma multiforme cells both in vitro and in vivo. Mol Carcinog 2014.

33. Petrasek J, Iracheta-Vellve A, Csak T, Satishchandran A, Kodys K, Kurt-Jones EA, Fitzgerald KA and Szabo G: STING-IRF3 pathway links endoplasmic reticulum stress with hepatocyte apoptosis in early alcoholic liver disease. Proc Natl Acad Sci USA 110: 16544-16549, 2013.

34. Wei J, Huang Q, Huang R, Chen Y, Lv S, Wei L, Liang C, Liang S, Zhuo L and Lin X: Asiatic acid from Potentilla chinensis attenuate ethanol-induced hepatic injury via suppression of oxidative stress and Kupffer cell activation. Biol Pharm Bull 36: 1980-1989, 2013.

35. Li SQ, Wang DM, Shu YJ, Wan XD, Xu ZS and Li EZ: Proper heat shock pretreatment reduces acute liver injury induced by carbon tetrachloride and accelerates liver repair in mice. J Toxicol Pathol 26: 365-373, 2013.

36. Lu XX, Wang SQ, Zhang Z, Xu HR, Liu B and Huangfu CS: Protective effects of sodium nitrite preconditioning against alcohol-induced acute liver injury in mice. Sheng Li Xue Bao 64: 313-320, 2012 (In Chinese).

37. Xie Q, Guo FF and Zhou W: Protective effects of cassia seed ethanol extract against carbon tetrachloride-induced liver injury in mice. Acta Biochim Pol 59: 265-270, 2012 